\title{
DA EXPERIÊNCIA ESTÉTICA À FILOSOFIA COMO PRÁTICA FORMATIVA
}

\author{
Carlos Alexandre Bellino de Albuquerque Sacadura ${ }^{1}$
}

Resumo: Pretende-se abordar a problemática da filosofia como prática formativa, tendo como paradigma a experiência estética enquanto via para uma formação ética que inclua as dimensões emocional, afetiva e criativa do ser humano (e não apenas a formação intelectual ou técnico-profissional), retomando assim as tradições filosóficas formativas da Paideia antiga, assim como as da autonomia e da Bildung modernas.

Palavras-Chave: Filosofia. Educação. Prática formativa. Experiência estética. Ethos

Resumen: El propósito del artículo es tratar de los problemas de la filosofía como una práctica formativa, tenendo por paradigma la experiencia estética como via para una formación ética que incluya las dimensiones emocional, afectiva y creativa del ser humano (no solamente la formación intelectual o técnicoprofesional), reanudando así las tradiciones filosóficas formativas de la antigua Paideia, así como las de la autonomía e de la Bildung moderna.

Palabras claves: Filosofía. Educación. Práctica formativa. Experiencia estética. Ethos.

\section{Introdução}

Este estudo incide na questão do valor formativo da Filosofia nos campos do Conhecimento, da Arte e da Ética. Embora representando dimensões autônomas da experiência humana epistêmica, estética e ética, podemos encontrar no seu modo de configuração um traço comum: o de serem modos de construção da experiência, implicando a mediação, reflexão, inovação, descoberta ou criação. Daí resulta também a sua dimensão educativa: se "o homem não nasce já feito", ou não nascemos humanos, tornamo-nos humanos através da educação segundo Kant, estas três instâncias são modos de construir o ser humano, educá-lo, no sentido de formá-lo. Educar o homem através da ciência - entendida não só em sentido estrito do conhecimento científico, como no de saber, indicado nos termos grego "episteme" e latino "sapientia" ou no de "scientia".

\footnotetext{
${ }^{1}$ Universidade Pública de Cabo Verde - Departamento de Ciências Sociais e Humanas e-mail: cabas@sapo.cv; carlos.sacadura@docente.unicv.edu.cv
}

SACADURA, Carlos Alexandre Bellino de Albuquerque. Da experiência estética à filosofia como prática formativa. Revista Sul-Americana de Filosofia e Educação. Número 26: maio-out./2016, p. 149-160. 
Kant já considerava que a interrogação sobre "O que é o homem?" englobava as do que posso saber e do que devo fazer, ou seja, do conhecimento $e$ da moral, da razão teorética e prática, às quais se poderia juntar a do "que me é permitido esperar?" Na esteira desta visão, pode-se considerar que a ciência, a arte e a ética são componentes da experiência formativa antropológica - a de tornar-se humano pela educação e cultura, expressa nos conceitos de "Paideia" e de "Bildung", de origem grega e alemã, mas revelando uma experiência universal. A formação filosófica permite desenvolver uma experiência - a experiência formativa -, que não é um dado, mas uma construção, sendo por isso abordada na perspectiva transcendental. Neste estudo, foca-se especialmente a problemática da formação a partir da experiência estética, vista como instância formativa paradigmática, porque assume uma dimensão cognitiva, ética, social e axiológica.

\section{A formação como nova experiência transcendental}

Se considerarmos a formação como uma modalidade da experiência, precisamos também de caracterizar as suas condições de possibilidade, estruturas, alcance e limites, ou seja, efetuar uma abordagem transcendental da experiência formativa. A referência a Kant e à sua filosofia transcendental impõe-se, porque a formação não se baseia na experiência empírica, no imediato, nem num pensamento "a priori", afastado do mundo e da vivência, mas numa experiência estruturada, implicando uma mediação conceptual, simbólica, discursiva, argumentativa, imaginativa, ética ou axiológica. Neste sentido, a formação implica tanto a experiência como a reflexão, o viver e o pensar.

Se a passagem pela filosofia Kantiana é incontornável para formular as bases de uma teoria e prática formativa, na medida em que a formação é um processo de estruturação do ser pessoal e social, e não um modo de experiência imediata, precisamos, por outro lado, de repensar o modo como na sua filosofia crítica se articulam o formal e o material, o sujeito e o mundo, o racional e o empírico, o "a priori" e o "a posteriori", de modo a superar uma perspectiva dicotômica do processo formativo que resultaria de uma simples transposição da filosofia transcendental para o campo educacional. O pensamento filosófico de 
Maurice Merleau-Ponty, interpretado por Theodore Geraets como um projeto visando a proposta de uma nova filosofia transcendental ${ }^{2}$, a reinvenção do "a priori" Kantiano efetuada por Mikel Dufrenne $e^{3}$, e a reavaliação atual do criticismo por Alain Renaut ${ }^{4}$ são trabalhos que podem fornecer as bases para esta releitura de Kant. Nas duas primeiras obras, encontramo-nos perante uma perspectiva fenomenológica da formação como abertura ao mundo vivido. Para passar do conhecimento à formação, a atitude transcendental pela qual um sujeito conhece um objeto que lhe é exterior, ou seja, a atitude de um espectador descomprometido que coloca o mundo diante de si para o conhecer, torna-se numa atitude de co-implicação entre o sujeito e o mundo, de uma reciprocidade segundo a qual o sujeito não é apenas uma parte do mundo objetivo conhecido pelas ciências, nem uma consciência de si soberana (perspectivas que o objetivismo científico e as filosofias da consciência tendem a separar e polarizar), mas um ser-no-mundo que se relaciona com ele não só através do conhecimento científico, mas também da afetividade, da imaginação, da criatividade.

Se a filosofia moderna, na esteira do "cogito" cartesiano e do sujeito transcendental Kantiano, com a sua afirmação de que "o eu penso acompanha todas as representações", desenvolveu a ideia do ser humano como consciência de si autônoma, a emergência das ciências sociais e humanas tendeu a considerá-lo como um objeto dependente do meio físico, biológico, social e histórico que o condiciona. Esta última tendência teve grande impacto nas teorias e práticas educativas, conduzindo a uma visão da educação como simples adaptação comportamental ao meio, segundo o modelo das psicologias comportamentais. Neste contexto, a filosofia assumiria um papel na defesa de uma concepção do processo educativo como formação da pessoa, de um "tornar-se pessoa" autônoma e livre, contra a massificação das sociedades contemporâneas.

\footnotetext{
${ }^{2}$ Cf Theodore Geraets, Vers une nouvelle philosophie transcendentale, La Haye, Martinus Nijhoff, 1991.

${ }^{3}$ Cf.Mikel Dufrenne, La notion d'a priori.Paris.PUF. 1959.

${ }^{4}$ Cf. Alain Renaut, Kant Aujourd 'hui, Paris, Flammarion, 2007.
} 
Nas suas obras $A$ noção de a priori ${ }^{5}$ e $O$ inventário dos a priori ${ }^{6}$, Mikel Dufrenne desenvolveu um dos projetos filosóficos que mais radicalmente repensaram a filosofia transcendental e a sua noção de a priori, conduzindo-o à elaboração da noção de a priori material. Para equacionarmos os fundamentos de uma filosofia formativa, estas noções são relevantes, porque permitem retirar ao conceito de forma a sua índole estritamente formal, conceptual, categorial, em suma, intelectual, para o devolver ao âmbito da expressão, da afetividade, da imaginação. Se a formação envolve as formas que estruturam a experiência, ela não é apenas formal, cognitiva, ou intelectual, implicando antes toda a variedade do campo da experiência humana. Outra vertente é a da relação entre o sujeito e o mundo: a capacidade formativa do sujeito é encarada, na filosofia transcendental kantiana, como uma capacidade para impor formas à experiência empírica de um mundo que lhe é exterior e visto como objeto, enquanto para Dufrenne o sujeito está já implicado num mundo, e a divisão sujeito-objeto é já recortada a partir da sua co-presença no seio de um mundo originário que é horizonte de um Ser englobante. Se entendermos a formação nesta ótica, não se trata de formar um sujeito constituinte que está perante o mundo para o constituir impondo-lhe formas, mas de pensar a formação como constitutiva de uma pertença originária a um mundo não apenas pensado ou conhecido, mas vivido.

Paul Ricoeur expôs claramente o alcance da reforma da filosofia transcendental kantiana e da sua noção de a priori efetuada por Dufrenne: “ Dufrenne quer corrigir a tradição Kantiana do a priori em dois pontos fundamentais: 1) para Kant, o a priori reside apenas no sujeito do conhecimento: é a subjetividade que constitui tudo o que há de válido nos objetos do conhecimento: 2) por outro lado, (...) todos os a priori kantianos estão votados à intelectualidade. À primeira tese, Dufrenne opõe um desdobramento do a priori: é, por um lado, uma estrutura que pertence aos objetos, que se mostra e exprime fora de nós, em face de nós; é, por outro lado, um saber virtual dessas estruturas,

\footnotetext{
${ }^{5}$ Cf. Mikel Dufrenne, La notion d'a priori, Paris, PUF. 1959.

${ }^{6}$ Cf. Mikel Dufrenne, Inventaire des a priori, Paris, Christian Bourgois. 1981.
} 
situado no sujeito humano. Dufrenne opõe à segunda tese um sentido concreto dessas estruturas objetivas, mais parecidas com fisionomias do que com relações de inteligibilidade, e um sentido carnal desse saber subjetivo, mais próximo do sentimento (...) do que da inteligência abstrata." 7

Para efetuar esta passagem de uma formação "intelectualista" a uma formação que inclui o sentimento, a afetividade e a imaginação criativa, a mediação estética é essencial. Ela permite redescobrir uma relação entre o sujeito e o mundo que não reduz o sujeito a uma parcela ínfima do mundo objetivo, e determinado por este, nem a um sujeito constituinte do mundo, "dono e senhor" dele. Esta polaridade entre objetividade e subjetividade, que marca a filosofia e as ciências humanas, releva de visões unilaterais, torna-se para Dufrenne numa afinidade fundamental entre o homem e o mundo, entre o a priori subjetivo pelo qual damos forma ou sentido ao mundo, e o a priori objetivo que é o mundo como sentido inesgotável, excedendo toda a objetividade ou conhecimento.

A reciprocidade entre o mundo e o ser humano redescobre-se assim como um outro modo de relação, que não assenta no poder ou no domínio, mas no sentimento de um reencantamento estético perante um mundo que se viu reduzido a um objeto pela ciência e técnica moderna e contemporânea: "Dufrenne exprime a sua própria felicidade de ser e sentir-se reconciliado com as paisagens da sua existência. (...) não é a ação conquistadora nem o pensamento dominador que me revelam o mundo como mundo (...) É o sentimento." ${ }^{8}$ Este sentimento de um habitar que se mostra como poético e não dominador, de um ethos que é uma forma de viver num mundo de sentido inesgotável, religa assim a inteligibilidade desenvolvida pela reflexão filosófica e a experiência estética revelada na arte.

\section{Da Estética à Ética: a formação como arte de viver.}

\footnotetext{
${ }^{7}$ Paul Ricouer, Lectures 2, Paris, Seuil, 1999, pp. 325-326.

${ }^{8}$ Idem, ibidem, pp. 330-331
} 
Desde Aristóteles, na sua Ética a Nicómaco, que se estabeleceu uma distinção entre moral e ética, embora nem sempre mantida. Essa distinção já aponta para uma arte da ética, ao considerar a moral ligada a princípios, normas, códigos e sua aplicação, enquanto a ética implica, não uma reprodução de normas, mas uma genealogia de valores, uma criação de si problematizada por filósofos como Nietzsche e Foucault. Em ambos há uma referência ao pensamento antigo, colocando-se Nietzsche na esteira da filosofia pré-socrática e dos trágicos helénicos, enquanto Foucault pretende retomar e reinventar as "práticas de si", que são práticas formativas, porque visam dar forma à vida e construir uma estética da existência. A arte de viver consiste numa prática da liberdade e numa formação que extrai da estética a ideia de que formar não é impor uma forma fixa à vida, mas conseguir imaginá-la e realizá-la em novas formas. Paul Ricouer confere à literatura este potencial formativo ético: a literatura reconfigura o real, abrindo-nos a novos mundos dignos de serem habitados e vividos. Também o sujeito deixa de ter uma essência ou identidade fixa, que seria a de permanecermos idênticos para além do fluxo temporal ou das alterações circunstanciais, para se tornar num processo de constituição de si, no qual outra instância estética - a imaginação - se torna fulcral. Se a prática da liberdade é uma possibilidade humana, a sua efetivação, a passagem do possível ao real, depende de uma "imaginação ética" que instale o sujeito em "territórios abertos" ao exercício da liberdade.

Esta perspectiva da ética como arte da criação de si conduz-nos, no âmbito formativo e pedagógico, ao que se pode denominar como uma "pedagogia da autopoiesis" - designação proposta por James Faubion no seu estudo sobre o pensamento de Foucault. $^{9}$ Afastamo-nos assim das perspectivas comportamentalistas do agir ético como resposta do sujeito ao meio propostas por algumas orientações das ciências humanas, para encarar a ética como mudança de si e das interações sociais. Enquanto as teorias do comportamento, de âmbito psicológico ou sociológico, incidem sobre as representações subjacentes à ação e

\footnotetext{
${ }^{9}$ Cf. James Faubion, Toward an Anthropology of Ethics: Foucault and the Pedagogies of Autopoiesis. In The Ethical. Oxford, Blackwell, 2003
} 
às atitudes que a determinam, ou seja, procuram determinar o significado inerente à conduta humana, a ética, como prática reflexiva da liberdade, constitui um modo de questionar, interrogar, problematizar o sentido, condições e fins da ação. É uma instância crítica, livre, reflexiva, dinâmica do agir. O ethos orientador da conduta liga-se à sociedade e cultura na qual se move mas, como instância problematizadora, pode questionar esses quadros socioculturais e efetuar escolhas que não são determinadas por estes, mas implicam uma criação de si, uma poiética ou forma de imaginação ética.

O trabalho de Foucault como sociólogo e historiador - áreas onde se destacou tanto como no campo filosófico, situando-se o seu pensar no cruzamento destes domínios - conduziu-o a considerar a importância do meio no comportamento: toda a ação ocorre no interior de uma "epystéme" - noção que significa uma certa ordem dos discursos que circulam num contexto histórico, cultural e social. Por outro lado, o seu pensamento crítico levou-o a afirmar a possibilidade de questionamento e reelaboração dos discursos e práticas interiores a essa epystéme e, assim, permitir as escolhas, encontrar novos territórios ou mapas orientadores do pensar e agir. A dicotomia entre os determinismos de vários tipos - econômicos, sociais, psicológicos, históricos - e os "decisionismos" pelos quais um sujeito soberano seria totalmente auto-determinado, ou seja entre um sujeito condicionado, heterônomo, e um sujeito incondicionado, absolutamente livre, encontra-se assim superada mediante uma ética que equaciona as condições sociais, históricas ou culturais da liberdade e da autonomia, em consonância com a proposta de Merleau-Ponty.

O que Foucault denunciava nas suas primeiras obras era “(...) o sujeito como substância lógica a-histórica, suporte trans-histórico de valores universais (...). O sujeito que é convocado nas suas últimas obras e nos seus Cursos no Collège de France (cujos títulos são eloquentes: "Subjetividade e verdade", "Hermenêutica do sujeito") (...) é um sujeito cujo modo de ser é histórico de parte 
a parte,(...) trata-se de pensar a história que conduz (...) à problematização geral de um sujeito ético (...)." 10

Se o sujeito moral depende da sua circunstância, é pela sua dimensão estética que ele é capaz de reelaborá-la, questioná-la, criticá-la. A arte torna-se assim numa condição da liberdade, aquela pela qual a inscrição do sujeito num mundo dado pode ser refigurada em mundos a constituir, e a sua experiência reconstruída, conduzindo a novos modos de ser. A experiência histórica constitui tanto um campo de condicionamento, sujeição e adaptação a normas de conduta (aspeto detectado pelas teorias do comportamento), como da sua problematização e da escolha de estilos de vida através dos quais o sujeito se forma e auto-constitui: "A história foucaultiana (...) não é nem uma história dos comportamentos (...) nem uma história das representações (...) mas uma história das modalidades da experiência constitutivas de um sujeito ético, (...) uma história da estruturação ética da existência, (...) das artes de viver, mediante as quais são propostas ao sujeito estilos de vida e onde se elaboram as suas escolhas. (...) Não é de acordo com uma separação do permitido e do proibido que se operam essas escolhas, mas segundo os cânones de uma estética da existência." 11

Podemos conceber a formação como uma prática filosófica que se desenvolve a partir de uma estética da existência ou, como também a designou Nietzsche, uma estilística da existência, entendendo "estilo" como forma de vida, envolvendo uma dimensão ética, que é a da escolha de uma forma de vida, entre múltiplas formas possíveis. A abordagem histórica/genealógica da ética permite-nos inventariar algumas destas formas, que podem inspirar a criação atual de novos modos de vida. O recurso à história do pensamento e da literatura da Antiguidade Clássica é feito a partir das preocupações do presente, mas não visa copiar os modos de vida ou o ethos enunciado nos textos filosóficos antigos, pretende antes lê-los como propostas que devemos, por nossa vez, retomar, recriar: "A abordagem foucaultiana da ética antiga é confessadamente motivada pelas

\footnotetext{
${ }^{10}$ Frédéric Gros, Michel Foucault, Paris , PUF, 2006, pp. 93-94.

${ }^{11}$ Idem, ibidem, pp. 97-100.
} 
preocupações do presente, e não por uma curiosidade desinteressada pelo passado. A explicação para as (...) interpretações foucaultianas encontra-se na sua preocupação em desenvolver atualmente (...) uma ética da autotransformação. (...) Foucault (...) distingue entre este núcleo da ética e o do código - um (....) conjunto coerente e sistemático de prescrições que podem ser fixadas, institucionalizadas e explicitamente formuladas (...), entre a moralidade enquanto codificada ou codificável, e a moralidade grega clássica (...) centrada quase exclusivamente em torno da ética - ou seja, o modo como cada um orienta por si próprio a sua conduta. Faz sentido atualizar a noção grega de epimeleia heuatou (...) desde que reconheçamos que esta re-ativação não é uma repetição, mas a criação de algo de novo." 12

As implicações desta perspectiva estética para a formação têm um grande alcance: ao religar o intelecto e as emoções, o pensar e o sentir, a Estética permite estabelecer as condições para uma formação que não dissocie estas dimensões do ser humano, abrindo caminho para uma dinâmica formativa sistémica e holística.

\section{Conclusão: a emergência de um novo paradigma formativo - a formação como prática filosófica}

Quando nos referimos à formação, aparecem logo vários conceitos a esta ligados, num espectro tão amplo como polarizado, da formação metodológica $e$ pedagógica, à técnico-profissional, estética, ética ou espiritual. A dimensão filosófica está presente em todas, através das suas áreas teoréticas e práticas, mas a sua função principal, como se procurou abordar neste estudo, pode ser a de apresentar-se como condição que torna possível uma formação integral do ser humano, nem unidimensional, redutora, uniforme ou unificada, na acepção de homogénea ou supressora das diferenças, nem fragmentada ou atomizada, nem total, na acepção de absoluta ou acabada, mas pluridimensional, aberta, relacional e sempre inacabada. Evocando um balanço da atividade da Escola Prática de Altos Estudos em 1961-62, feito por um docente, Pierre Hadot refere-se ao processo que consiste em formar para competências técnicas e profissionais, sem atender àquela

\footnotetext{
${ }^{12}$ Timothy o'Leary, Focault and the Art of Ethics, London, Continuum, 2002, pp. 82-84.
} 
que é a função formativa da filosofia, a de formar os espíritos, ou formar para a vida, levando-nos a refletir sobre a possibilidade de hoje, no século vinte e um, conseguirmos efetuar esta formação filosófica: " Caímos na rotina mais vazia e vemos desaparecer o que faz o essencial das humanidades, que é formar os espíritos." Será que, neste início do século XXI, as coisas mudaram realmente?" 13

Se entendêssemos por formação integral uma visão sistemática ou totalizadora, iríamos defrontar-nos com uma impossibilidade, a de pretender construir um sistema total do saber, pretensão que poderia ser exequível nas grandes construções sistemáticas do mundo antigo e moderno, mas hoje inalcançável. É aí que uma releitura dos textos antigos ou renascentistas e uma revisitação do seu saber-viver nos pode guiar hoje: em vez de encará-los como uma arquitetura de conceitos visando um sistema completo de conhecimento, fazer uma experiência da sua leitura como ensaios ou percursos inacabados, por analogia com o próprio inacabamento da vida. O significado de uma formação entendida como prática filosófica pode ser o de uma relação entre os seus discursos ou textos e a existência, o modo de vida, atitude que projetam. Pierre Hadot propõe uma reactualização - e não uma cópia - dos textos filosóficos da Antiguidade enquanto modelos de formas de vida, tendo este processo sido retomado por filósofos contemporâneos como Husserl, Wittgenstein ou Foucault.

Começa por mostrar como esta tradição filosófica que não é a de informar, explicar ou conceptualizar, mas a que visa formar, ligar o discurso e a vida - a experiência da filosofia como Paideia - se perde na modernidade: "Não se poderia dizer que o fim de um sistema moderno é o de dar uma explicação do mundo, do homem, e que, inversamente, a principal finalidade de um texto filosófico antigo é a de transformar o auditor ou leitor? (...) Lembro a fórmula de Victor Goldshmidt a propósito dos diálogos de Platão, que é absolutamente extraordinária; disse que Esses diálogos visam, não informar, mas formar. E penso que, com efeito, isto é válido para toda a filosofia antiga, porque o discurso filosófico (...) destina-se (...) a formar o espírito, ensinar-lhe a orientar-se no pensamento e na vida. No fundo,

\footnotetext{
${ }^{13}$ Pierre Hadot, La Philosophie comme manière de vivre, Paris, Albin Michel, 2001, p. 82.
} 
quando Werner Jaeger intitulou o seu livro Paideia, significando a palavra paideia formação, penso que teve uma excelente intuição: para os gregos, o que conta é a formação do corpo e do espírito." 14

Retomar hoje a tarefa da filosofia como prática formativa, na esteira da Paideia grega e da Bildung alemã, implica repensar as suas fronteiras com a arte, de modo a ligá-la a outros modos de expressão e experiência da vida e do mundo, diversos do argumentativo, lógico ou conceptual, ou seja de modo a integrar outros a priori, como o afetivo ou o imaginativo: "Se virmos na filosofia uma forma de vida, e não apenas um sistema coerente de conceitos e proposições, isto poderá ter muitas consequências para a relação entre a filosofia $e$ as outras disciplinas literárias e artísticas. Um romance, um poema, até a pintura, a música, podem representar uma forma de viver e por vezes provocar uma transformação na nossa forma de vida. Então, a filosofia como disciplina não se fecha em si mesma mas abre-se a todas as descrições das nossas maneiras de viver."37

Um caso paradigmático desta articulação entre experiência estética $e$ filosófica é o do romance de formação, do qual podemos encontrar uma expressão cabo-verdiana no Chiquinho, obra do poeta e romancista Baltazar Lopes ${ }^{15}$, onde o itinerário existencial do personagem indicado no título se identifica com o do homem e mulher de Cabo Verde. O movimento estético claridoso, sem esgotar as manifestações literárias cabo-verdianas, exprime de diversos modos este itinerário, situando-se numa fronteira entre a literatura e a filosofia. A experiência estética pode assim constituir uma mediação entre uma aprendizagem/formação intelectual e uma formação integral, que se abra às múltiplas dimensões da existência e à possibilidade de mudar a vida - pessoal e social - através da formação como reinvenção de si e do mundo, num processo que não se encerra numa forma definitiva mas, à semelhança da arte, é aberto e criativo.

\footnotetext{
${ }^{14}$ Idem, ibidem, pp. 149-150 ${ }^{37}$ Idem, ibidem, p. 222.

${ }^{15}$ Cf. Baltazar Lopes, Chiquinho,Lisboa, Cotovia, 2008.
} 


\section{REFERÊNCIAS}

DUFRENNE, Mikel (1959). La notion d'a priori. Paris: PUF.

DUFRENNE, Mikel (1981). Inventaire des a priori. Paris: Christian Bourgois.

GERAETS, Theodore (1991). Vers une nouvelle philosophie transcendentale. La Haye: Martinus Nijhoff.

GROS, Fréderic (2006). Michel Foucault. Paris: PUF.

HADOT, Pierre (2001). La philosophie comme manière de vivre. Paris: Albin Michel.

LOPES, Baltazar (2008). Chiquinho. Lisboa: Cotovia.

O'LEARY, Timothy (2002). Foucault and the Art of Ethics. London: Continuum. RENAUT, Alain (2007). Kant Aujourd'hui. Paris: Flammarion.

RICOEUR (1999). Lectures 2. Paris: Seuil. 